Psychology of Language and Communication 2018, Vol. 22, No. 1

\title{
Sciendo
}

DOI: $10.2478 /$ plc-2018-0010

\author{
THOMAS WIBEN JENSEN \\ University of Southern Denmark, Denmark
}

\section{HUMOR AS INTERACTIONAL AFFORDANCES: AN ECOLOGICAL PERSPECTIVE ON HUMOR IN SOCIAL INTERACTION}

\begin{abstract}
In adopting new theoretical advancements within linguistics and ecological psychology, this paper investigates humor from an ecological perspective in naturally occurring social interaction. In doing so, it is claimed that the notions of language as coordination and values-realizing can provide a new understanding of humor as it appears in human interaction. This argument will be unfolded as a rethinking of Wallace Chafe's notion of nonseriousness (Chafe, 2007) that re-conceptualizes Chafe's idea of a 'mental state' of nonseriousness in terms of interactional affordances and values realizing. This perspective is laid out in in-depth analyses of video recordings of two real-life examples from different settings: two siblings playing and a sequence from a couple-therapy session. It is claimed that both examples of interactional humor can be explained by re-conceptualizing humor as a distinct way of being together. Thus, the emergence of humor is enabled by a shift in the coordinative dynamics rather than by a transfer of semantic 'content' from a speaker to a hearer. Finally, humor is investigated as a temporal phenomenon integrating immediate 'here-and-now' environmental features with socio-cultural expectations on a longer time-scale. In this way humor is viewed as a particular type of values-realizing activity that constrains our actions, re-directs our attention, and thereby enables us to act in a more playful and joyous manner.
\end{abstract}

Key words: social interaction, humor, affordances, interpersonal coordination, values realizing

\section{Introduction: Interactional humor}

This article investigates humor from an ecological perspective as "a mode of interaction" (Norrick \& Chiaro, 2009). That is, humor viewed as a relational phenomenon emerging from a re-organization of the shared

Address for correspondence: Thomas Wiben Jensen, University of Southern Denmark, Campusvej 55, 5230 Odense, Denmark. E-mail: twj@sdu.dk 
attention among participants in social interaction. The object of study is the way that humor and laughter emerge as spontaneously occurring phenomena in the fast flow of naturally occurring human interaction. This implies another take on humor and laughter than the one traditionally dominating research in humor studies. Thus, the focus here is not on 'planned humor' such as well-prepared jokes, pun, or punchlines (Flieger, 1991; Koestler, 1964; Perlmutter, 2000; Pinker, 1994; Raskin, 1985), nor is it on well-defined linguistic figures such as irony, sarcasm or counterfactuals (Bryant \& Gibbs, 2015; Gibbs \& Colston, 2007). Instead, the aim of the article is to explore and understand humor as something more basic than jokes, more interactive than semantic incongruity (Attardo \& Raskin, 1991), and more embodied than social positioning (Hay, 2000; Samermit \& Gibbs, 2016). A bigger, more complex canvas is needed.

I will call the phenomenon under scrutiny interactional humor. This term is used to differentiate humor as a distinct form of behavior different from the more common idea of humor as 'an inner feeling' or a personality trait. Furthermore, it highlights humor as a spontaneous phenomenon in social interaction different from both planned humor in staged discourse such as stand-up comedy, television shows and so on, and also from carefully developed humor in cultural products of any kind (satire, literature, film, music, commercials etc.). The term is partly related to the notion of conversational joking (Ervin-Tripp \& Lampert, 2009; Norrick, 1993,) but differs from it in terms of not being about jokes per se, nor having a primary focus on the social functions of humor.

Interactional humor cannot be reduced to the use of words, timing, expressive behaviors, laughter and inter-bodily dynamics; still, it cannot be properly understood without a consideration of the entanglement of these aspects either. Interactional humor is never a uniquely individual endeavor in the sense that it relies heavily on co-construction, collaboration, cooperation, and coordination among different participants to 'get off the ground'. In this light, interactional humor is something we do together if we do it at all. It is part of our languaging behavior (Thibault, 2011), the way we 'do language' as an interpersonal activity (Fusaroli, et al., 2014; Jensen and Pedersen, 2016). This of course points to the fact that having fun and laughing together during a conversation is one of the most fundamental ways in which we attach to each other and thereby acquire a sense of well-being and adherence. But which features in the course of social interaction invite such actions? What are the enabling conditions for interactional humorous actions? These questions will be at the core of the investigation of this article.

\section{Theory and analyses}

The investigations are conducted from an ecological perspective (Gibson, 1979), with reference in particular to language as coordination (Cowley, 
2011; Harvey, 2015; Jensen, 2014a; Kravchenko, 2009; Love, 2004; Raczaszek-Leonardi and Nomikou, 2015; Steffensen, 2009; Thibault, 2011; Trasmundi, 2015), and the closely related notions of affordances (Chemero, 2011; Gallagher, 2017) and values-realizing (Hodges, 2009, 2017). Traditionally, humor has been conceptualized as primarily an individual phenomenon originating in the mind of the 'joke teller' and explained by reference to the intentions of an individual speaker or performer (Flieger, 1991; Koestler, 1964; Perlmutter, 2000; Pinker, 1994; Raskin, 1985). However, in this study, the focus is on how humor is enabled by shared attention and cooperation in terms of co-thinking and co-feeling among different participants in interaction. This includes a focus on humor as the product of an emerging and enacted field of potential actions embedded in a conversational ecology of languaging features such as posture, gesture, voice, facial movements, intonation, hesitations etc. along with verbal actions. The key point is that humor is seen as realizing a distinct type of interactional affordances that is informed and driven by variables and forces operating at different time scales.

The analytical section is based on two empirical examples from video recordings of people interacting; the first example is a sequence of two children, a sister and younger brother, interacting in a humorous way, while the second example concerns adults, a married couple in couple's therapy, jointly responding to an awkward situation in a humorous way. The examples are quite different but a unifying aspect is the spontaneous inter-bodily coordination that paves the way for a sudden shift in the interactive flow. Thus, the analyses center on how the interplay between words and bodily action alters the possible ways of perceiving a given situation and thereby makes interactional humor possible. In this perspective, interactional humor is seen as a distinct type of values-realizing activity (Hodges, 2009), or a directedness in the dialogical system (Steffensen, 2012) that allows for a shift in perspective and (inter)actions of a more playful, joyous and explorative character.

This way of looking at humor, in turn, has implications for an anti-representational approach to the discussion on content or 'the meaning of words' in the fields of radical embodied cognition and distributed language (Chemero, 2011; Cowley, 2011a; Harvey, 2015; Jensen, 2014; Jensen and Pedersen, 2016; Love, 2004; Steffensen, 2009). I will argue that interactional humor does not chiefly arise as a consequence of the content or representational value of the words used as such, rather interactional humor is tied to the attentional value of words and phrases; the way in which they re-organize the shared attention and thereby transform the direction and structure of the situation ${ }^{1}$. This argument will be unfolded as a rethinking of

${ }^{1}$ Of course, this is not necessarily an either-or choice. The attentional value of the words used is always tied to both the present context with its situation-specific interactional affordances as well as the conventional 
Wallace Chafe's notion of nonseriousness (Chafe, 2007). The aim is to show that Chafe's idea of a 'mental state' of nonseriousness, supposedly underlying laughter and humor, can be rethought as a particular kind of values-realizing. In a conversation interactants perceive a field of potential actions or affordances; consequently, what we traditionally call 'humor' can be seen as a way of realizing a less usual type of conversational affordance.

\section{Language as coordination}

In recent years, an increasing number of scholars have begun to investigate and understand language (spoken language in particular), not as primarily a code system, nor as a mean of mental representation, but rather as a sophisticated mean of embodied and social coordination (Cowley, 2011; Fusaroli, et al., 2014; Harvey, 2015; Jensen, 2014; Kravchenko, 2009; Linell, 2009; Love, 2004; Raczaszek-Leonardi \& Nomikou, 2015; Steffensen, 2015; Thibault, 2011; Trasmundi, 2015). A shared assumption in many of these studies is a distinction between first-order language, or languaging, that is language as a whole bodied sense-making behavior, different from second-order language as a temporal and socially molded constraint on the first order behavior. In relation to human conversation this view on language entails a shift of focus away from both individually produced utterances and their logical underpinnings, as in speech act theory (Searle, 1969), as well as on micro-sociological sequential structure and the reproduction of social normativity, as in conversation analysis (Hutchby \& Wooffitt, 2011). Instead the prime focus is on coordination. As such, recent studies show that two or more people engaged in joint tasks, both merely 'social' or goal-oriented towards some kind of problem solving, often come to adapt their behaviors through a trajectory of compensatory complementary behaviors meaning that "these behaviors influence one another locally and incrementally, making the whole conversational performance itself a kind of self-organizing synergy" (Dale, et al., 2013, p. 56). Thus, a crucial difference in talking about coordination rather than for instance 'communication', is that the latter still - to some extent - entails an idea of two separate positions (sender/receiver - speaker/hearer) that exchange something (thoughts, ideas, feelings, directives, metaphors etc.) between them in some manner, while the former emphasizes the adaptive and self-organizing nature of human interaction to the degree that human dialogue is viewed as a functional whole (Dale, et al, 2013; Fusaroli et al., 2014): Human behavior, including speaking, forms a living system that is only divided into separate entities of sender-receiver as part of an analytical process of isolating and ascribing meaning to individuals.

meaning of the words; only the conventional meaning is never fixed in social interaction since it will always be part of the flexible action potential of the ongoing situation. 
Furthermore, an ecological perspective centers on the entanglement and coordination of inter-bodily activity and verbal actions in the here-and-now with situation-transcendent features of cultural conditions and past experiences on longer time-scales. A central assumption is that social interaction needs to be studied within a perspective that attempts to account for both the great level of detail in the-here-and-now as well as social and cultural dimensions outside of the present situation influencing the ongoing dialogue. An ecological perspective on language offers such a way of looking at language that incorporates many levels of constraints that dynamically organize the in-the-moment interactive behavior and experience, including evolutionary forces, bodily dynamics, cultural and social conditions, knowledge of language (lexical, grammatical, pragmatic), institutional settings and so forth. In relation to interactional humor one particularly relevant phenomenon is the dialogical notion of third parties. Third parties concern an aspect of the curious fact that a conversation never happens in isolation:

In a conversation one does not just talk with some concrete other who is present there and then; as a participant, one also orients to, exploits, and plays with ideas, traditions and communicative activity types that exist from before and which are carried further in and through the situated interaction. (Linell, 2009, p. 99)

As shown in the analyses below a central dimension in interactional humor is the human ability to see the current conversation from a third person perspective ${ }^{2}$; a look from an outside field of certain normative and culturally loaded structures and expectations that are nevertheless re-enacted in the present situation. Seen from an ecological point of view these 'non-local' patterns are interactional affordances for different types of action.

\section{Interactional affordances as values-realizing}

The notion of affordance derives from James Gibson's theory of perception (Gibson, 1979) and offers an interesting perspective on how the environment guides and scaffolds action and perception; a perspective that can prove relevant also in relation to a new understanding of humor. Affordances are often explained as action possibilities, which, according to Gibson, are what the environment "offers the animal, what it provides or furnishes, either for good or ill" (Gibson, 1979, p. 127). The core idea is that the agent (animal or human) perceives the possibilities for action within an environment directly. Direct perception means that an agent perceives, not neutral pieces of information that need to be put together, but instead a world of value in accordance with the agent's distinct abilities: The seagull directly perceives the surface of the water as an opportunity to land (or look for food),

${ }^{2}$ Likewise, in various studies related notions such as represented discourse, or reported speech, repetition, and footing have been used to analyze and understand humor in interaction (See for instance: Attardo, 1994; Norrick, 1993; Tannen, 2005 and 2007). 
while humans may see the same surface as opportunity to swim or dip a toe. Within a contemporary ecological perspective, Anthony Chemero has convincingly argued that affordances are profoundly relational phenomena existing between the animal/human and the environment as possibilities for action: "Affordances are neither properties of the animal alone nor properties of the environment alone. Instead, they are relations between the abilities of an animal and some feature of a situation" (Chemero, 2013, p. 191).

From an ecological perspective, the principal affordance of face-to-face encounters is the possibility to share action: The possibilities for co-action, co-thinking and co-feeling in the flux of social interaction (Jensen and Pedersen, 2016). The immediate inter-bodily dynamics enabled by the interactive environment in the here-and-now of "doing language", or languaging (Thibault, 2011), with other people afford impulsive action and thought in a joint space. One such action opportunity can be the impulse to act together in a humorous way and whereby realizing a distinct set of values.

Here it is important to bear in mind that the ecological notion of values, closely related to the notion of affordances, is very different from the standard definition of values in contemporary philosophy or sociology. The standard view often apprehends values as properties that are reached over time in and through social processes and cultural traditions. On this view, there is nothing intrinsic about values, which are essentially a matter of social consensus, what a given community decides to treat as valuable or not valuable. In contrast to this (somewhat relativistic) view Hodges claims that:

..all actions, whether driving or conversing with a colleague, are constrained and legitimated by multiple values. Values are the real goods that actions must realize sufficiently for an ecosystem to exist; thus values are obligatory demands that define what constitutes good driving or a good conversation. (Hodges, 2011, p. 138)

Within this ecological framework values are conceived as the fundamental conditions that allow, enable, and restrain the directedness of actions within our physical as well as social environment. This places values in a heterarchy rather than a hierarchy that 'in itself' determines right and wrong. Similar to the notion of languaging, this approach attempts to tie together the motivation for simple mundane actions, like reaching out for another cup of coffee, to large scale value judgments of making the right decision when being placed in a moral dilemma. The basic claim is that the act of defining and recognizing actions, cognitions, and emotions is to engage in a value-activity in itself. Following from this, Hodges proposes a perspective on conversing as a perceptual system in which we constantly orient, integrate, and try to find our way in order to invite responsible action: "Conversing, like driving, is an ecosystem defined by values. Among the values that define it are clarity, coherence, comprehensiveness, and complexity" (Hodges, 2009, p. 140). 
As a sub-category of the overall value of complexity we can place interactional humor as a specific type of directedness in the ecological system of conversation. Engaging in humorous interaction is a specific type of value-realizing activity. Often interactional humor will entail a momentary disregard of the other prevalent values - clarity, coherence, comprehensiveness - or put another way; the 'normal criteria of relevance' are put aside for a brief while to pave the way for an attention towards other aspects of the situation. Our attention is suddenly altered and the possibility of acting in a different way emerges. The possibility for a new 'path' of engagement makes it possible to interact with each other in a completely different manner characterized by a larger degree of playfulness, surprise and joy.

\section{Nonseriousness in an ecological perspective}

As a further illustration of the potential of an ecological account of humor I will now briefly turn to the notion of nonseriousness (Chafe, 2007). This notion has been developed within a cognitive linguistic framework, but I will argue that it could benefit from an ecological interpretation. According to Chafe, nonseriousness is a basic feeling underlying both laughter and humor.

The feeling of nonseriousness, then, whether it is elicited by humor or nonhumor, can be viewed as a safety valve whose purpose, simply stated, is to keep us from taking seriously things it would be counterproductive to take seriously. (..) This feeling, manifested in these ways [by laughing], may have evolved as an adaptive response to whatever situations early humans encountered in which it would be counterproductive to act or think seriously. Such situations were kept from entering a person's serious cognitive repertoire, a person's knowledge of how the world really is. (Chafe, 2007, p. 11)

Thus, the notion of nonseriousness draws on experiences where an inconsistency arises between how we normally perceive the world and how a situation presents itself. Chafe gives an example in which we see a dog looking at a newspaper while moving its head as if it was reading. It would be counterproductive to take the reading dog seriously; instead we indulge in a pleasant feeling of nonseriousness and typically start laughing. However, a seemingly reading dog is rare to encounter. A less unusual example - pointing more to the cooperative basis of nonseriousness - could be me seeing a friend walking across a room or a large space and suddenly stumbling over something and falling to the ground. If it looks serious, if he seems shocked or perhaps injured, I will not laugh but instead aid and make sure he is all right. If not, if he looks fine, only overwhelmed with surprise, I will perhaps not treat it seriously and instead laugh, especially if my friend is laughing too. Seen from this light, the feeling of nonseriousness is often cooperatively built among several participants in relation to 
a reorganization of our attention allowing for a shift in perspective. To describe (interactional) humor as primarily an inner feeling (of nonseriousness), or a mental state, as Chafe does, is to miss its fundamental embeddedness in a conversational ecology.

Thus, we can reconsider non-seriousness, in the light of the notions of affordances and values-realizing, as a distinct type of attention that makes possible a particular kind of coordination, rather than an inner feeling. This reconceptualization of nonseriousness places it in the midst of the interactional dynamics of conversation instead of being 'locked' in the heads and minds of the various participants in interaction. Notwithstanding these reservations, Chafe's notion of nonseriousness still has something vital to offer in terms of recognizing that we need to look at interactional humor as something more basic than jokes, irony or sarcasm in the sense that, at its core, it concerns a fundamental shift in attention. This dimension is often downplayed or overlooked in other more popular theories of humor, such as incongruity theory.

\section{Incongruity theory and its hidden written language bias}

Today many psychological or neuroscientific studies of humor investigate what kind of situations are most likely to evoke humorous responses and how they affect the neural activity of subjects (McGraw and Warren, 2014; Ramachandran, 1998). Such studies seek to scientifically investigate humor by asking participants to perform one of a variety of tasks, such as rate how funny some event was, how much it made them smile or laugh, or they let the subjects be exposed to different types of humorous stimuli, in comparison to non-humorous stimuli (Amir, et al., 2013; Coulson, 2001). The experimental findings from such studies are then interpreted as pointing to what evokes humor and how the brain can detect something as humorous.

Many of these studies are motivated by some version of incongruity theory (Koestler, 1964), now often referred to as General Theory of Verbal Humor (GTVH) (Attardo \& Raskin, 1991), building on the assumption that resolution of incongruity in semantic frames is fundamental to any kind of humorous expression. The basic tenet in incongruity theory is that humor by default contains an unexpected, often sudden, shift in semantic frame that need to be resolved. Most jokes, for example, establish two different frames of reference that are somehow in conflict. At the punchline, these two frames get resolved and a humorous reaction emerges. Consider for instance these two examples:

A young lady was talking to the doctor who had operated her.

"Do you think the scar will show?" she asked. 
“That will be entirely up to you", he said (Attardo, 1994, p. 7).

Two behaviorists have sex; one says to the other afterwards:

"That was great for you; how was it for me?" (Boyd, 2004, p. 1).

Such 'clever jokes' involve an intentional, and well-planned, build-up of expectations that are broken in order to produce a humorous effect. "We wait for one thing, and we get another thing that is quite different but that nevertheless has a certain suitability" (Ziv, 1984, p. 90). The jokes entail a strong element of surprise and a subsequent retrieve of sense vital to humorous action. However, written jokes are often carefully crafted over many iterations and edits, in contrast to interactional humor as a more spontaneous phenomenon. Thus, incongruity theory seems prone to the so called written language bias (WLB) (Linell, 2005). In short, WLB concerns a tradition in both linguistics and in the humanities in general in which the models, methods and frameworks for describing phenomena occurring in spoken language environments have been taken over by from the tradition of describing and explaining written language and its inherent structures. Thus, from an ecological perspective the main problem with GTVH is that many types of humor, actions and situations we for some reason find funny, are not planned. They cannot depend on preparation and working over. Instead they rely on a completely different set of interpersonal affordances characterizing human conversation.

\section{Interactional studies of humor and the ecological alternative}

To some degree a distinction between planned and more spontaneous types of humor has already been addressed by interactional studies of humor (Attardo, 1994; Norrick, 1993; Norrick \& Chiaro, 2009). This literature distinguishes conversational joking from other types of more planned joking. Conversational joking is seen as improvised drawing heavily on context features. Still, the focus is primarily on jokes. However, during a conversation we may find a situation humorous just by looking at someone's face, by noticing a distinct conversational style in a certain setting, by hearing a characteristic tone of voice, or when our gaze meets that of our interlocutor's in a particular situation. Such situations are transient and spontaneous and cannot be understood as jokes per se. That is, they do not necessarily entail a narrative structure, a build-up of expectations to be broken, or a conscious play of words.

Furthermore, the interactional approach entails a shift of focus away from (what defines) humor as such while instead focusing on the social functions of jokes and humor; how humor may be part of breaking "the ice, fill awkward silences, smooth the way for requests, and build group solidarity" 
(Norrick, 1993, p. 1) ${ }^{3}$. However, rather than purely sociological, sociolinguistic or conversation-analytic focus this study has an ecological research interest. Such a vantage point entails, amongst other things, a bio-social perspective on language and cognition (Cuffari \& Jensen, 2014; Steffensen, 2015; Trasmundi, 2015) that strives to study facets of human behavior, such as humor, in situ without committing to either a biological/essentialist or a cultural/sociological standpoint that respectively excludes the other. Instead, the assumption is that there is no contradiction between seeing language and other types of adaptive flexible behavior:

..as biogenic and as social, simply because sociality is our human way of being nature. This assumption both precludes the bio-reductionism that ignores supra-individual (i.e. social or cultural) dynamics and the socio-reductionism that ignores the metabolic and ecological foundations of human existence. (Steffensen, 2015, p. 117)

The way we 'do humor' is at once biogenic and social. Thus, to gain a more comprehensive understanding of humor, we need to investigate what makes it possible (as a human universal) as well how it functions in a social context (as a social variable). From an ecological perspective humor is seen as a particular kind of adaptive flexible human behavior in a social realm; "a human way of being nature" (ibid.). In this way, interactional humor might be an even more basic phenomenon than assumed in interactional studies of humor. To further explore this perspective, let us now look at the analyses.

\section{Analytical part}

As mentioned in the introduction the analytical examples consist of video-recordings of children as well as adults interacting, and in that sense the two examples are quite different. Still, the two examples are carefully chosen since they can highlight different dimensions of interactional humor while at the same time pointing to shared fundamental features. Involving children, the first example is in many ways much simpler than the second, it involves less spoken interaction and fewer social constraints are at stake. Likewise, the second example is more complex being embedded in a specific social setting (couple's therapy) and relying much more on a breach of social expectations. Still, the idea behind analyzing data involving children as well as adults is to highlight shared enabling conditions cutting across the differences in age, maturity and situation. Both situations are constituted by a sudden shift in the shared attention of the interlocutors relying on a precise

\footnotetext{
${ }^{3}$ Likewise, there is a large amount of literature dealing with the ways that humor varies in terms of social sub-cultures, level of education, occupation, social status, gender and maturity. See for instance: Goodman, 1992; Kramarae, 1981; Lakoff, 1975. Thus, it is a well-documented phenomenon that groups of people (friends, family members, classmate, colleagues etc.) can develop a certain type of humor among them that enhance the internal cohesion or solidarity within the group and at the same time may exclude others who are unfamiliar to this type of humor (Meyer, 2000). In particular, this has been studied in terms of gender (Hay, 2000, Schnurr and Holmes, 2009) and ethnicity (Vine, et al., 2009).
} 
inter-bodily coordination briefly affording another way of being together in fast flow of interaction. In this sense, there is a line from the more basic type of humor emerging in the first example to the more complex humor developing in the second example. The basic argument is that the contours and trajectory of this line indicate something fundamental about the way that both humor and words work in social interaction.

\section{Analysis one: "Is it funny?"}

Laura, aged 5, and Jack, aged $1 \frac{1}{2}$, are sister and brother ${ }^{4}$. Like many siblings at that age they enjoy spending time together, often making up small games and laughing together. In this short sequence, they are sitting next to each other on the pavement in front of their house being filmed by their father. At a first glance the excerpt might only look like a sister and brother "fooling around" but a closer analysis reveals how a distinct type of values-realizing enables the emergence of interactional humor in this situation.

\section{EXAMPLE 1}

Participants: J: Jack, L: Laura

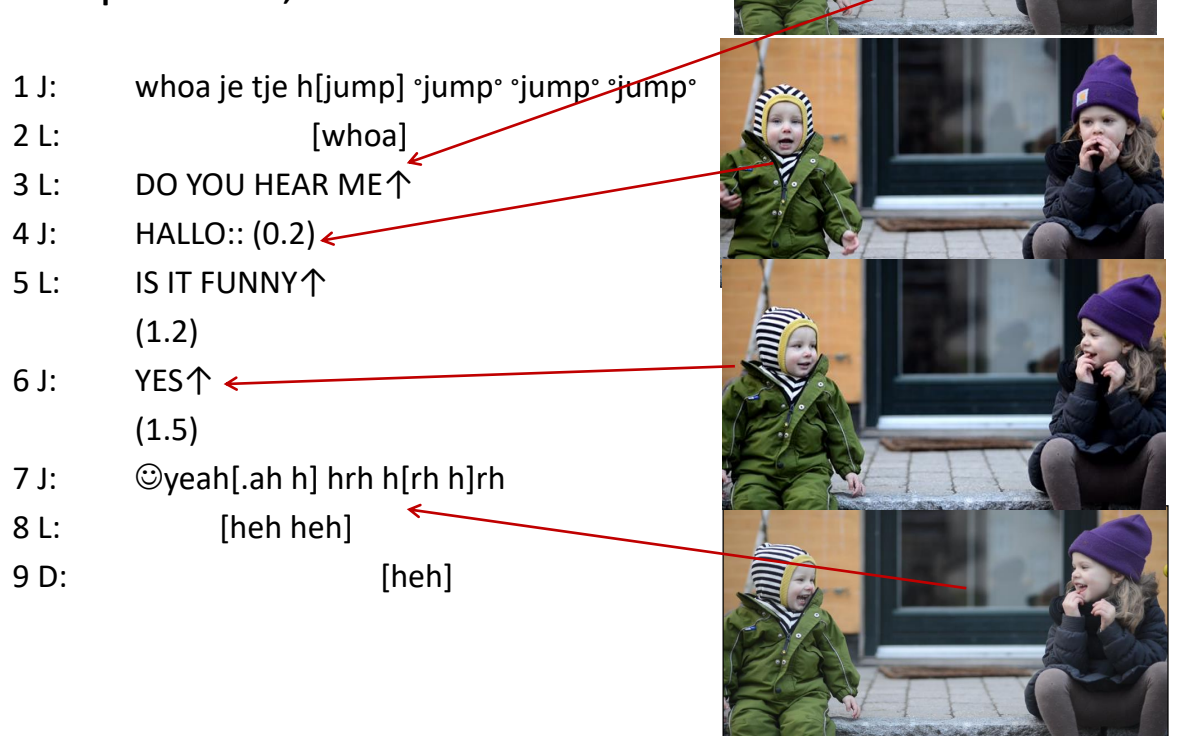

Seven seconds into the sequence something unexpected happens. Suddenly Laura utters DO YOU HEAR ME (1. 3) with high volume and both her hands around her mouth as if shouting to someone far away (see first picture) while also looking into the air. Now, albeit Jack has been jumping

\footnotetext{
${ }^{4}$ Both names are pseudonyms. A written form of consent was signed their father beforehand. The language
} used in the video clip is Danish but has been translated into English. 
away from his sister (while babbling and articulating the word 'jump' several times -1 . 1), they are still sitting within an optimal hearing distance less than a meter from each other. Therefore, it would seem strange to interpret it as a sincere factual question. Rather the wordings of Laura mark a playful or joking comment, most likely commenting on the fact that Jack is moving away from her. Furthermore, the way that the utterance stands out, in terms of posture, gesture and volume, also marks an informal invitation to a game-like activity in the sense that it affords further action in the same manner. This is supported when looking at Jack's response: Immediately he picks up on his sister's verbal action by uttering HALLO (1. 4) with high volume and prolonged vocal sound, again as if calling someone further away (see second picture) indicating a continuous focus on the pretended distance between them. Thus, we can note that already here they are about to establish a distinct type of attention towards the interpersonal situation; an attention towards the affordances for transforming the activity at hand into a more playful act.

Subsequently, in line 5 Laura explicates these action possibilities by asking IS IT FUNNY $\uparrow$ with high volume and rising intonation in the end. Jack does not answer right away and seems to ponder about whether this is actually funny (from the perspective of $1 \frac{1}{2}$ year old), but after a pause of 1.2 seconds he affirms his sister's question with a YES $\uparrow$. Still, the actual laughing does not begin until Laura and Jack look at each other in the pause following line 6 (see third picture). Until now both Laura and Jack have looked ahead, not at each other (as part of the game accentuating the imagined distance between them), but just as Jack repeats his answer in line 7 (yeah) with a quirky and smiley voice their eyes meet and they start laughing (see fourth picture). For a short moment in the interactive flow - a little less than 3 seconds - Jack and Laura build a temporary 'interpersonal geography' in which they share attention and explore the affective affordances of the situation. In short, they laugh and have fun together.

\section{The value of non-seriousness}

Considering Chafe's notion of non-seriousness in an ecological perspective we can see that the emergence of a humorous or non-serious way of interacting is in fact rooted in a reconfiguration of their attention that allows for a particular kind of coordinated activity. That is, a value-realizing activity embedded in the value of complexity in the sense that it is rooted in a self-reflective and meta-discursive verbal action (IS IT FUNNY $\uparrow$ ) asking the question: Are we having fun? This question, in turn, opens up for a new 'path' of engagement or different ways of interacting with each other. In this sense the adjacency pair sets up "discrepant kinds of awareness" (Gibson, 1979, p. 282) that allow for different ways of interacting with each other in an affective and playful manner. The exact nature of this kind of values realizing is part 
of the value of complexity in the sense that it directs and re-organizes their joint attention towards the quality of the ongoing activity itself. That is, the adjacency pair (question - answer) restructures the interactional dynamics in the sense that the previous patterns are now treated as instances of 'having fun' - and thereby the fun arises! Laura's verbal action is naming their joint experience and that naming constrains their experience of what is happening. Laura draws on temporal experience and her ability to detect invariants in interactional patterns which crystalizes the experience. In turn, Jack confirms this experience in answering his sister's question and acknowledges that their previous activity can be seen as an exemplification or an instance of what is normally referred to as 'having fun'.

In doing so, they also confirm an affective alliance that is only possible by engaging in the values-realizing activity of having fun in this concrete situation. The term 'situation' is here to be understood in a broad sense including the physical surroundings (sitting next to each other on the pavement), the inter-bodily dynamics (Jack jumping on his backside, Laura shouting, gesturing and looking into the distance), the social circumstances (being filmed by their father), the interpersonal relation between Laura and Jack as sister and brother, and finally the differences in age and cognitive maturity. This is clearly an asymmetrical type of interaction in which Laura to some extend "teaches" her younger brother how to recognize something as funny - in a sense it can be seen as an informal exercise in taking a language stance in order to have fun. All of these circumstances are enabling conditions for the particular kind of values-realizing leading to the humorous interaction. Via the shift in attention the interactional dynamics gets reconstructed, viewed in another light as part of what counts as funny activities. Laura's question to her little brother comments on the activity in which they have been engaged. Thereby the level of awareness is raised and their attention is turned towards a particular aspect of the situation: Can we look at what we are doing here as a way of having fun? Thus the 'fun' does not arise as a consequence of the representational value, or the content, of the words used but as a consequence of their attentional value; the way in which they re-organize the shared attention and thereby transform the 'purpose' and structure of the situation. The central point being that the fun arises in and through this particular kind of values-realizing activity. It now becomes possible to see the situation in which they are a part in a new alternative perspective; a perspective that enables a humorous type of interaction.

\section{Analysis two: "A pause for reflection"}

This longer sequence comes from a larger set of recordings of couple's therapy sessions featuring a therapist and married couples ${ }^{5}$. As an introductory

\footnotetext{
${ }_{5}$ The recordings were undertaken in relation to my Ph.D. project in collaboration with the Danish Imago Center. A written form of consent was signed by all participants beforehand. The language used in the video clip
} 
exercise this couple is asked to mention one thing about the other that they appreciate and value; a request that turns out to be harder to fulfil than one should expect. In this example, it is the pause in line 5, or rather the way that the pause is being treated, that elicits the humorous interaction dominated by laughter. As in the first example the humorous interaction and laughter is enabled by a particular kind of values-realizing activity that allow for a specific type of attention and coordination, yet here in a more elaborate and cognitively sophisticated manner.

\section{EXAMPLE 2}

Participants: T: Therapist, M: Man, W: Woman

$1 \mathrm{~T}:$

$2 M$ :

$3 \mathrm{~T}:$

$4 \quad M$ :

5

6

7

8

9

10

11

12

13

14

15

16

M:

$\mathrm{T}:$

$\mathrm{M}$ :

$W:$

$\mathrm{M}$ :

one thing (1:2) that I w[ould like to tell you]

[it has to be something] concrete

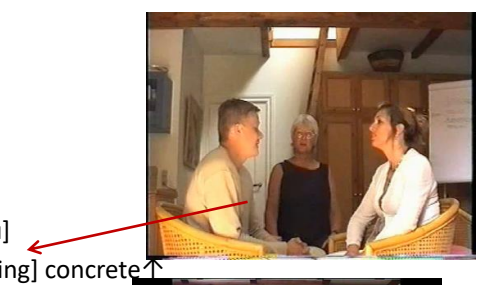

it has to be absolutely

M: $\quad$ okay it has to be absolutely concrete ${ }^{\circ}$

(3:0)

M: $\quad$ hhch heh hh

M: [no(h) h] $)$ NOW THERE SHOULANOTBE TOO LONG A PAUSE

M: $\quad$ FOR REFLECTION:-)

T: $\quad\left[{ }^{\circ}\right.$ just try $\left.{ }^{\circ}\right]$

W: [heh heh heh heh heh heh hah $\mathrm{h}$ heh heh heh heh heh heh heh]

[.h.h.h huh huh h h]

[there must be just something .h.hah]

[heh heh oh yeah uh an amazi(h h)ng PRESSURE :-)HERE:)]

[heh heh heh hah hah hah heh heh heh heh hah hah hah]

ihr.h .h well okay

W: h.hh mhm
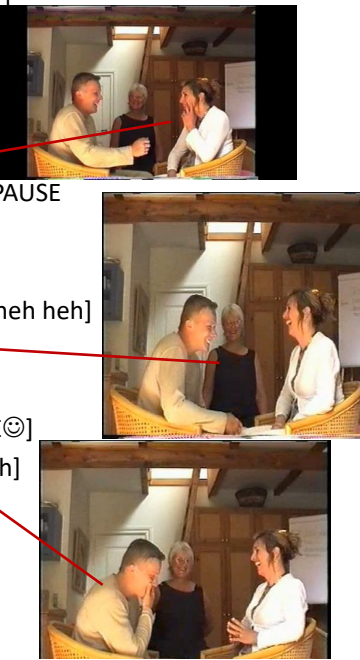

In line 1 the therapist asks the man and wife to recall and articulate something positive about each other. The request is even confirmed by the therapist in line 3 as an answer to the man's question if it needs to be something specific. Thus, they both need, on the spot, to come up with something positive to say about their spouse. However, the following pause lasts almost three seconds which in the fast flow of interaction is a considerable time. Then in line 6 the pause is suddenly disrupted by $\mathrm{M}$ moving his shoulders up and down in small rhythmical movements while making hearable outbreaths surrounding and interwoven in the articulation of "no (h) w". M follows up on this in line 7-8 by uttering now there should not be too long a pause for reflection with high volume and smiley voice. These actions are immediately reflected by 
a change in W's behavior from sitting still while looking into the distance to a distinct smiling-and-gazing-behavior directed towards M. In a flash, they engage in an interactive expressive vocal and bodily behavior that quickly turns into joint laughter.

\section{Interactional humor and self-reflective action}

How is this laughter triggered then? As in the first example, the notions of affordances and values-realizing are useful in explaining this occurrence of laughter. The key lies in the way the 3 second pause is attended to by the husband and wife: The pause is perceived as an instance of 'non-action' at a time when action is required. Thus, the pause acquires a meaning beyond that of a mere breathing space or delay. It is dealt with as an instance of something problematic which in turn has a humorous potential. Again, it is a re-orientation that affords paying attention to the features of the ongoing activity itself, adding another layer to the conversation, and thereby enhancing the level of complexity, that elicits the humorous perspective.

It is a values-realizing activity of treating action, or rather in this case non-action, as instances of something beyond that of the action itself. In this case, such a values-realizing activity has a clear social function too. $\mathrm{M}$ and $\mathrm{W}$ are jointly managing the social pressure arising in and through the pause by commenting on it and laughing together. In treating the pause as an instance of something problematic by commenting on it and laughing, the situation is also socially evaluated. As investigated by the conversation analyst, Gail Jefferson, laughter in interaction in certain situations has the social effect of dealing with sensitive topics. Something similar is at stake here; by engaging in a humorous interaction and laughing behavior the couple mutually deals with the troublesome fact that they were not, on the spot, capable of recalling something valuable about each other. At the same time the humorous perspective is made possible by a joint positioning that also treats "the problem" as something funny. Thus, the values-realizing activity is reconfiguring the joint attention of $\mathrm{M}$ and $\mathrm{W}$ in the interactional situation in the sense that they become able of seeing their own activities in another light. By treating the pause as an instance of non-action they raise their own awareness of how to interpret the situation. It is self-reflective action since it incorporates their real-time activity with a "gaze" from an outside position, and in that sense, it is nested in a larger second order values-realizing activity of contemplating about the nature of the interaction itself.

\section{Third parties and interactional humor}

A closer look at the trajectory of the laughter in this sequence reveals two significant 'peaks' of laughing in terms of volume, intensity, duration and postural sway: in line 10-11 (overlapping) as well as line 13-14 (also partial overlapping). Both of these peaks have a sequential placement right after 
verbal and gestural actions; they seem to function as multimodal responses to what have just been said (and done by means of gesture) suggesting that these actions are not only built into the very structure of laughing, but also contribute significantly to its development. Thus, in line 7-8 $\mathrm{W}$ makes a very distinct gesture-and-posture (see second picture) exactly at the point when M says PAUSE FOR REFELCTI::ON: :) thereby providing a visual feedback and image reflecting the wordings. Likewise, in line 13 a similar (albeit not identical) gesture-and-posture is performed by $M$ (see fourth picture) simultaneously with his own speech on an amazi(h)ng PRESSURE :). We can call these repeated gesture-and-postures an emblematic 'thinking-gestureand-posture'. They have the characteristics of placing the right hand or fingers either on one's cheek (first instance) or in front of the mouth (second instance) while wrinkling brows and looking downwards (somewhat like the famous "The thinker" sculpture by Auguste Rodin). These gestural actions have a complementary function to the ongoing speech in the laughing sequence since they both complement the meaning of the verbal actions of having to think hard whilst under pressure. As such, they provide an image of 'concentration' that in turn add to the initial stance in the sense that the gestural actions also 'comment' on the situation by evoking an image of a more general character. It is an image of 'someone' who needs to think hard.

This is a good example of how an outside third party perspective is introduced into the conversation in the sense that the gestural "thinking-actions" accompanied by the verbal actions (now there should not be too long a pause for reflection - an amazing pressure here) depict the present situation seen from an outside perspective. The verbal actions comment on the present situation by displaying an awareness of the delicacy of the situation while the gestural actions "paint" a caricatured image of the issue at stake (this can also be seen as a hyperbole, or use of exaggeration as a rhetorical device, see Gibbs, 2007). The fact that they did not immediately remember something positive about each other may challenge and confront the standard ideas, and ideals, of how a marriage should be. This perspective, the normative generalized perspective of marital relationships, is reflected in these gestures and the verbal actions following them. These actions highlight the distance between how a marital relation ought to be (according to a certain normative perspective), and how it in fact presents itself in this situation. The gestural "thinking-actions" enlarge their difficulties (of not being able to remember something positive about each other) and thereby reveals the distance between ought and is, and in the conscious awareness of this distance lays a deeply humorous potential. 


\section{Conclusion: A distinct way of being together}

As mentioned in the introduction to the analyses these two examples may seem very different in terms of the form and type of interactional humor that is being enacted. Clearly the first example is in various ways much simpler (and shorter) than the second example. It is simpler in the sense that the emergence of humor is primarily tied to a reorganization of the shared attention. This reorganization provides a simple category, or a naming (having fun), for their experience which in turn produces a humorous and joyful effect. Of course, this has to do with the fact that the example involves children, and in particular the little brother is basically learning to connect a certain experience with a particular characterization - and in that sense the interactional humor in this example is closely connected to activities such as play and (informal) learning. The second example is much more complex in the sense that shift in attention towards the pause is embedded in a longer socio-cultural time-scale depicting contextual expectations (of how a marital relationship ought to be) and the ability to see how these expectations are broken by the present situation. Furthermore, the build-up of the interactional humor in this example has a longer trajectory, elaborated by means of both words and gestures.

Nonetheless, the two examples share a fundamental feature in the cooperative build-up of a humorous interaction as a more basic phenomenon than for instance jokes or puns. In both cases the humorous effect is enabled in-and-through a shared re-orientation of the participant's attention towards features in the environment embedded in a values-realizing activity of focusing on specific embodied features of the interaction itself. In this way, the level of attention and reflection is simultaneously raised - and thereby the level of complexity. It is a basic reflexive action oriented towards the ongoing interactional dynamics. In the first example, it is the vocal and inter-bodily activities of the two children that are treated as an affordance for naming the activity as an instance of 'having fun' - and thereby actually having fun. In the second example, it is the duration of the pause that is treated as an affordance for engaging in the situation in a completely new manner that eases the social pressure while enhancing the interpersonal and inter-bodily relation by being humorous. Thus, both examples entail the following characteristics, (i) humor as a distinct way of being together embedded in a values-realizing activity that allow for a particular kind of behavior, (ii) an emergence of humor enabled by a shift in the coordinative dynamics rather than a transfer of semantic 'content'.

However, these processes of coordinative dynamics in the here-andnow need to be embedded in a larger reflexive enculturation (Taylor, 2010) in which culturally informed ideas and beliefs about language are played out in the interactional dynamics. The socio-cultural expectations entail a level 
of constraints that put our real-time experiences into a temporal perspective which in turn makes it possible to keep experiences apart in order to compare and evaluate them. Thus, a third characteristic needs to be included, (iii) humor as a temporal phenomenon integrating immediate 'here-and-now' environmental features with socio-cultural expectations on a longer timescale. This basic temporality is vital for our ability to experience anything as humorous or funny. As children, we learn to laugh at certain things, for instance someone making 'a funny face', only when the muscular movements of the face get connected to previous experiences of faces labelled as funny. "See, daddy looks silly now". In such a case, it depends on our ability to:

(...) produce ordered variances that allow the invariants (i.e., stabilities) to be detected. Just as children learn what objects are moveable or not, and how so, they learn what aspects of utterances are moveable or not, and how so.In both cases they learn something of what those movements afford (Hodges, 2007, pp. 598-599)

Such "movements" allow for interactional humor to emerge. Repeated experiences with wordings used in different situations form the basis of connecting, comparing, relating and contrasting events (with or without the use of words) that have happened before with the present situation.

Much more work - experimental as well as based on naturalistic data - is needed to substantiate the claims of this article. Still, looking at humor from an ecological perspective seems a promising new way to engage in a phenomenon that has been dealt with from a large variety of perspectives. To sum up, in this article it has been argued that interactional humor does not, in its most basic form, rest on exchange of semantic content between a speaker and a hearer, nor is it merely an individual psychological phenomenon. It cannot be reduced to psychological motivations or emotional responses in individual speakers. Nor is it just social. It cannot be reduced to alignment, cooperation, keeping social coherence or enforcing social exclusion. Rather, humor is nested in the realization of values in the sense that it specifies actions enabling us to act together in a manner which is completely different from other types of behavior. In this way, an ecological perspective conceptualizes interactional humor as a type of values realizing activity that directs us, our attention and our actions, towards a different kind of exploration of the present conversational affordances. An exploration that, for a brief while, makes it possible to dispense from our regular conversational tasks and enjoy a different perspective on the situation we are in.

\section{References}

Amir, O., Biederman, I., Wang, Z., \& Xu, X. (2013). Ha ha! versus aha! A direct comparison of humor to nonhumorous insight for determining the neural correlates on mirth. Cerebral Cortex, 62, 35-43. 
Attardo, S., \& Raskin, V. (1991). Script theory revis(it)ed: Joke similarity and joke representation model. Humor, 4(3), 293-347. doi:10.1515/ humr.1991.4.3-4.293

Attardo S. (1994). Linguistic Theories of Humor. Humor Research 1. Amsterdam: Walter de Gruyter

Boyd, B. (2004). Laughter and Literature. A Play Theory of Humor. Philosophy and Literature, 28, 1-21.

Bryant, G. \& Gibbs, R. W. (2015). Behavioral complexities in ironic humor. In G. Brône, K. Feyaerts, \& T. Veale (Eds.), Cognitive linguistics and humor research (pp. 147-166). Boston, MA: De Gruyter Mouton.

Butovskaya, M. L. \& Kozintsev, A. G. (1996). A Neglected Form of QuasiAggression in Apes: Possible Relevance for the Origins of Humor. Current Anthropology, 37(4), 716-717

Chafe, W. 2(007). The Importance of Not Being Earnest. The feeling behind laughter and humor. Amsterdam. John Benjamins.

Chemero, A. (2011). Radical Embodied Cognitive Science. Cambridge, MA. A Bradford Book.

Coulson, S. (2001). Semantic leaps: Frame-shifting and conceptual blending in meaning construction. New York, NY: Cambridge University Press. doi:10.1017/CBO9780511551352

Colombetti, G. \& Krueger, J. (2015). Scaffoldings of the affective mind. Philosophical Psychology, 28(8), 1157-1176.

Cowley, S. J. (2011). Distributed Language. In S. J. Cowley (Ed.), Distributed Language (pp. 1-15). Amsterdam: John Benjamins.

Cuffari, E. C. \& Jensen, T. W. (2014). Living Bodies: Co-enacting Experience. In C. Müller, A. Cienki, E. Fricke, S. H. Ladewig, D. McNeill, \& J. Bressem. Handbook: Body - Language - Communication Vol 2 (pp. 2016-2025). Berlin: Mouton de Gruyter.

Dale, R., Fusaroli, R., Duran, N., \& Richardson, D. C. (2013). The selforganization of human interaction. Psychology of Learning and Motivation, 59, 43-95.

Ervin-Tripp S. \& M. Lampert, M. 2009. The occasioning of self-disclosure humor. In N. R. Norrick, and D. Chiaro (Eds.), Humor in Interaction (pp. 3-28). Amsterdam: John Benjamins.

Flieger, J. A. (1991). The Purloined Punch Line. Baltimore. MD: Johns Hopkins University Press.

Freud, S. (1905/1960). Jokes and Their Relation to the Unconscious. New York, NY: Norton.

Fusaroli, R., Raczaszek-Leonardi, J., Tylén, K. (2014). Dialog as interpersonal synergy. New Ideas in Psychology, 32, 147-157.

Gallagher, S. (2017). Enactive interventions: Rethinking the Mind. Oxford: Oxford University Press. 
Gibbs R. W. \& Colston, H. L. (Ed). (2007). Irony in Language and Thought. A Cognitive Science Reader. New York, NY: Lawrence Erlbaum Associates. Gibson, J. J. (1979). The ecological approach to visual perception. Hillsdale, NJ: Lawrence Erlbaum Associates.

Goodman, L. (1992). Gender and humor. In F. Bonner, L. Goodman, R. Allen, L. Janes, \& C. King (Eds.), Imaging women: Cultural representations and gender (pp. 296-300). Cambridge: Polity.

Grice, P. (1975). Logic and conversation. In P. Cole, J. Morgan (Eds.), Syntax and semantics. 3: Speech acts (pp. 41-58). New York, NY: Academic Press.

Harvey M. I. 2015. Content in languaging: why radical enactivism is incompatible with representational theories of language. Language Sciences, 48, 90-129.

Hay, J. (2000). Functions of humor in the conversations of men and women. Journal of Pragmatics, 32, 709-742.

Hodges, B. H. (2007). Good prospects: ecological and social perspectives on conforming, creating, and caring in conversation. Language Sciences, 29, 584-604.

Hodges, B. H. (2009). Ecological pragmatics: values, dialogical arrays, complexity and caring. Pragmatics \& Cognition, 17(3), 628-652.

Hutchby I, \& Wooffitt, R. (2011) Conversation Analysis. Cambridge: Polity Press.

Jefferson, G. (1984). On the organization of laughter in talk about troubles. In J.M. Atkinson \& J.C. Heritage (Eds.), Structures of social action: Studies in conversation analysis (pp. 346-369). Cambridge: Cambridge University Press.

Jensen, T. W. 2014: Emotion in languaging: languaging as affective, adaptive, and flexible behavior in social interaction. Frontiers in Psychology. Cognitive Science, Vol 5, Article 720. doi: 10.3389/fpsyg.2014.00720

Jensen, T. W. (2014a) New perspectives on language, cognition, and values. Journal of Multicultural Discourses, 9(1), 71-78.

Jensen, T. W. \& Pedersen, S. B. (2016). Affect and affordances: The role of action and emotion in social interaction. Cognitive Semiotics, 9(1), 97-103.

Koestler, A. (1964). The Act of Creation. London: Hutchinson.

Kramarae, C. (1981). Women and men speaking: Framework for analysis. Rowley, MA: Newbury.

Kravchenko, A. (2009). The experiential basis of speech and writing as different cognitive domains. Pragmatics \& Cognition, 17(3), 527-548

Lakoff, R. (1975). Language and woman's place. New York, NY: Harper Colophon.

Love, N. (2004). Cognition and the language myth. Language Sciences, 26, $525-$ 544.

Meyer, J. C. (2000). Humour as a double-edged sword: Four functions of humour in communication. Communication Theory, 10, 310-331 
McGraw, A. \& Warren, C. (2014). The humor code: A global search for what makes things funny. New York, NY: Somin \& Schuster.

Norrick N. R. (1993). Conversational Joking: Humor in Everyday Talk. Indiana University Press.

Norrick N. R. \& D. Chiaro (Eds.). (2009). Humor in Interaction. Amsterdam: John Benjamins.

Perlmutter, D. D. (2000). Tracing the origin of humor. Humor, 13(4), 457-468.

Pinker, S. (1994). The Language Instinct. New York, NY: Harper Perennial.

Provine, R. R. (2000). Laughter. A Scientific Investigation. New York, NY: Viking.

Raczaszek-Leonardi, J. \& Nomikou, I. (2015). Beyond mechanistic interaction: value-based constraints on meaning in language. Frontiers in Psychology, 6, 1579 .

Ramachandran, V. S. (1998). The neurology and evolution of humor, laughter, and smiling: The false alarm theory. Med Hypotheses, 51(4), 351-354. doi:10.1016/S0306-9877(98)90061-5

Raskin, V. (1985). Semantic Mechanisms of Humor. Boston, MA: Reidel Publishing Co.

Samermit, P. \& Gibbs, R. W. (2016). Humor, the body, and cognitive linguistics. Cognitive Linguistic Studies, 3(1), 32-49.

Schnurr, S. \& Holmes, J. (2009). Using humor to do masculinity at work. In N. R. Norrick, \& D. Chiaro (Eds.), Humor in Interaction (pp. 101-124). Amsterdam: John Benjamins.

Steffensen, S. V. (2009). Language, languaging, and the extended mind hypothesis. Pragmatics and Cognition, 17, 677-697.

Steffensen, S. V. (2012). Care and Conversing in Dialogical Systems. Language Sciences. 34(5), 513-53

Steffensen, S. V. (2015). Distributed Language and Dialogism: Notes on nonlocality, sense-making and interactivity. Language Sciences, 50, 105-119.

Tannen, D. (2005). Conversational Style: Analyzing Talk Among Friends. New Edition. Oxford: Oxford University Press.

Tannen, D. (2007). Talking Voices: Repetition, Dialogue, and Imagery in Conversational Discourse. Cambridge: Cambridge University Press.

Thibault, P. J. (2011). First-Order Languaging Dynamics and Second-Order Language: The Distributed Language View. Ecological Psychology, 23, 210-245.

Trasmundi, S. B. (2015). The cognitive ecology of human errors in emergency medicine: an interactivity-based approach. Unpublished Ph.D. dissertation. University of Southern Denmark, Faculty of Humanities. 
Vine, B., Kell, S., Marra, M., \& Homes, J. (2009). Boundary-marking humor: Institutional, gender and ethnic demarcation in the workplace. In N. R. Norrick, \& D. Chiaro (Eds.), Humor in Interaction (pp. 125-139). Amsterdam: John Benjamins.

Ziv, A. (1984). Personality and Sense of Humor. New York, NY: Springer. 